\title{
Identifying and managing cross cultural differences in the classroom: A case study of USIU
}

Judith J. Jefwa

\begin{abstract}
Many learning institutions are now designed to cater to the needs of students and staff from different cultures. The United States International University (USIU) in Kenya is no different. It provides learning opportunities to learners from different nations and regions of the world. When these learners and other staff come into the new culture, they often experience culture shock because the culture they now embrace is different from what they have been socialized into back in their own culture.
\end{abstract}

This paper examines the extent to which differences in cultural orientations affect learners' abilities to pursue academic programs effectively. We interviewed only a small number of learners since we were interested more in the narrational data and in few instances used statistical evidence.

\subsection{Introduction}

As more and more universities open up around the world, it is becoming increasingly clear that many people are crossing borders in order to get an education. When these people move from their "home" cultures into new cultures, they often experience culture shocks that can inevitably lead to poor performance even though the students may have been academically able within their own home schools. Culture shock refers to the psychological frustration one goes through when after going to a new culture one finds that he or she cannot cope in the new culture because the rules of socialization are different from what one is used to.

Moving to a new culture is a complex experience. The host and the newcomer each comes into this experience bearing different values, perceptions, traditions, rules and regulations of how one needs to behave. This often causes conflicts.

Given that many classrooms in Kenyan universities have now become heterogeneous in terms of the learners that populate them, this paper attempts to identify the factors that intervene in successful learning experiences of learners. While making reference to The United States International University (USIU) in Kenya, the paper examines the information provided by students in the institution concerning cultural differences that often make it difficult for them to perform well in class. We also offer insights on how these experiences can be managed for effective learning.

Although there may be many variables that may affect the learning process in a classroom, in this study we have focused on the following variables:

- Personal backgrounds of learners. 
- Diversity of language use in the classrooms.

- The learning styles of learners vis- a-vis the teaching styles of teachers.

In this study, we sampled about 60 students from different programs in the USIU. However, although statistical evidence was used to elucidate various aspects of the study, we were more interested in the narrational data presented by the learners.

\subsection{Learners' personal backgrounds}

About $80 \%$ of the learners interviewed come from the upper and lower middle class backgrounds. $10 \%$ come from the upper class and an equal number come from the lower class. It is ironical that even though a majority of them come from comfortable economic backgrounds many of them have had their school work suffer because of non payment of or delayed payment of fees. The reasons that the students gave for this problem were varied. They included a simple lack of money, inability of parents and guardians to access loans for fees in good time; parents and guardians having many children to pay fees for and parents simply being too busy to pay fees.

The non payment of fees normally causes a lot of strain on the learners. One of the most shocking aspects of this is that if fees are not paid then the student is denied access to key institutional infrastructure that enables effective learning to take place. For example, they cannot access the computer lab and course text books. According to the learners, the most disturbing classroom culture is that where some lecturers call out loudly the names of fees defaulters. This frustrates and humiliates learners. The learning process becomes a burden for the learner who knows that his or her non payment of fees will be a problem sooner than later.

Another parameter investigated is that of the students' religious background. Many of them professed that they belong to any one of the religions in existence in the country. About $70 \%$ are Christians, $20 \%$ Muslims and $10 \%$ belong to the Hindu and other religions. While a majority of them indicated that their religion does not affect their learning, about 3\% (all of them Christian) indicated that because they are staunch Christians, they find themselves judging others harshly in class especially within the classroom where interaction is in very close proximity. One student said "I tend to be self-righteous towards some students". They are prejudiced against learners who dress "obscenely" or who come to class smelling of alcohol. This especially affects learning during group work. Such students are also shocked at the casual manner that religion and God are treated in classroom discussion. This often irritates the overly religious learners and in a way this affects their learning.

This study also asked students to explain how their living arrangements affect their learning. We found out that nearly $50 \%$ of the learners live near the university but another $50 \%$ live away from the campus. Of this last group about $40 \%$ come to school by public means of transport, $10 \%$ use their own means of transport while the rest use the University's hired buses. The problem with the public means of transport is that they are unreliable. The vehicles do not keep time and to make it worse they are often caught up in traffic snarl-ups. Consequently, the students often come late to class. This in itself may not be a big problem. However 
students who attend classes by lecturers who tend to be monochronic time users, suffer penalties because they only allow lateness of up to 15 minutes (as stated in the USIU student hand book). After this, roll call is taken and anyone coming into class after this is deemed to be absent. In USIU, five absences automatically results in a failure (F grade). Some learners are forced to drop the class when they realize they are headed for failure. This fate also affects those that come to college with the university's hired means of transport. Sometimes the buses are also caught up in the traffic jams making it difficult for learners to get to their classes in good time.

A touchy issue that often distracts learners from performing well in class is that of familial obligations. Often, many hours are lost because students and sometimes teachers have to attend to relatives, who are sick, attend wedding and funerals and other pressing family problems. Students also often take time off to "just hang out with friends and family members".

These familial obligations often distract learning because absences make the students miss out on key elements taught in a lesson they may not have attended. They find it hard to catch up with missed lessons. Sometimes lecturers too are forced to hurry through lessons in order to make up for missed classes and when they organize make-up classes some students also fail to attend them.

A final aspect of students' background on which responses were made was that of dressing. Although $90 \%$ of the learners said that the other students' dress code does not affect their learning, however, $10 \%$ of them (all of them male) seemed to have a problem with skimpily dressed women students who expose parts of their bodies. They indicated that "poor" dress code often affects their concentration. Some of the students also indicated that they also expect their lecturers to be dressed formally and "decently" for effective learning to take place.

\subsection{Verbal language Diversity in the Classroom}

A second variable that we examined in this research is that focusing on how diversity in verbal language use can affect learning. Language is a means by which we communicate our thoughts, feelings, intentions, desires and knowledge to others. It suffices here to say that language allows for learning to take place in the classroom. This is because:

- Language permits one "to pool knowledge and to communicate with others - by linking individuals into communities of shared identity" (Samovar, L.A et al, pp 166).

Having said this though, we realize that often communication breakdowns occur because of the different ways in which language is used. Language use is shaped by cultures and because cultures are diverse, then so too is language use. Some of the language problems identified by the learners as sources of misunderstanding in the classroom include: 
Judith J. Jefwa 123

a) Problems of accents: Accents refer to the way individuals pronounce words. For many people in Africa, their first language of socialization is their native language or "mother-tongue" also referred to as L1. When these people learn a second language (L2) the L1 often interferes with the L2 because some sounds in L2 do not exist in L1. They are then replaced with the closest similar sound. This results in accent problems. Among the Kikuyu's, Meru's and Embu's languages of Kenya the /1/ sound does not exist thus they replace it with the $/ r$ / sound. This results in involuntary slips of the tongue which are referred to as "shrubs" in Kenya. Thus in their use of the English Language for example, library becomes ribrary, lip becomes rip etc. The Meru's and Embu's also have a problem of pre-nasalizing consonant sounds. Thus when they speak English boy will become mboy, girl will be pronounced as ngirl etc. Among the Luhyia's in Kenya, the sound /p/ is replaced by the sound /b/ thus pot becomes bot, boy becomes poy etc, the Luhyia's also replace the /d/ with $/ \mathrm{t} /$ and /g/ sound is replaced by the / $/ \mathrm{k}$ sound resulting in such "shrubs" as tok instead of dog, Bik instead of pig and class instead of glass. One can only imagine the intercultural communication breakdown that occurs in the classroom of students taught by teachers who are accent challenged. Many students also have similar challenges and with students and teachers in USIU coming from very diverse cultures from within and outside the country, the accent barriers can prove to be quite a challenge to effective cross cultural learning.

b) Lack of language proficiency. Many learners who come from countries where English is not the language of instruction often fail academically in USIU where English is the language of instruction. Cummins (1984) says that if students only have basic interpersonal skills (BICS) they cannot adequately "function in high-level academic situations" (cited in Gollnick and Chinn, pp 240). Some students who come from Rwanda, Burundi, Sudan and Ethiopia where English is not the language of instruction and who have not mastered the English language well, lack the ability to understand teachers instructions, get information from learning material or even write academically viable assignments.

\section{c) Code mixing and code switching}

According to Kaviti (2006), bilingual and multilingual speakers worldwide use two or more languages within the same communication. This results in "code mixing" and "code switching". Code switching refers to "language alteration across sentence boundaries, code mixing refers to language alternations within sentence boundaries" (The Nairobi Journal of Literature, pp 72). However, according to Kaviti, most studies use the term code switching to refer to both types of language alternations. In Kenya, people use English, Kiswahili and one or more native languages. Many of them, especially the youth also use Sheng or Engsh which are pidgins or "mixed" languages consisting of words and sentences from the languages mentioned above. Many Kenyan youths use this mixed languages as do others from other countries like Nigeria, Cameroon, Liberia and Ghana because these languages are, according to Gitonga (2008), "a form of youth identity" and "their way of life" (Iraki, pp 35). Often these mixed languages 
find their way into the classroom. Students and even teachers use them involuntarily or voluntarily in the classroom and this may hinder effective learning. Almost $90 \%$ of the Kenyan students interviewed said that they have used Sheng/Engsh in class and sometimes have been asked by teachers and other learners to explain the meaning of what they had said. Sometimes no explanations are required or asked for, since it is assumed that all students in the class have understood what has been said. Often this is not the case. Many learners also use Sheng/Engsh in its myriad forms in written assignments. This then becomes a major bone of contention between the learner and teacher with the learner feeling that he or she has been unfairly pinned down for using a language that he or she is comfortable with.

Diversity in the use of language can therefore be considered a major hindrance to the learning process at USIU.

\subsection{Learning and teaching styles}

From our questionnaire responses it would appear that many learners in USIU are encultured towards accepting the visual mode of teaching/ learning since about $98 \%$ prefer the use of power point in the classroom. However what is most shocking is that a majority of them do not like reading and understanding books and articles selected for them by their teachers for their out of class reading. They dislike library research; the reasons given for this state of affairs vary and include:

- They are not able to understand what is found in the course texts

- They are not able to get relevant information from books

- Course texts are not interactive

- Making own notes from course texts does not just work

- It is time consuming and unreliable

- Some course texts contradict the lecturers' point of view.

One of the most outrageous responses was, "we pay fees to be taught, not to go and find "stuff" for ourselves".

Many prefer handouts and lecture notes by their instructors.

Most learners feel that finding out information for themselves is time consuming and too involving. They claim that they have to do so many courses that they need short summarized notes.

Another way in which students learn is through group work and individual work assignments. The ratio of those who preferred group work to those who preferred individual assignments is almost 50:50. Those who prefer group assignments indicate that it allows them to share views about a subject amongst their peers while those who prefer individual assignments indicate that they make them more responsible for their work. It also allows them to do the work at their own pace which is often much faster than doing it in groups. 
The research also sought views concerning the manner in which they respond to questions in the classroom and the classroom atmosphere they prefer. $80 \%$ of the respondents indicated that they think of themselves as introverted, reflective learners who think about responses before answering questions and $20 \%$ are impulsive and extroverted learners. They all agreed that they prefer learning in highly energized classes where mutual respect for the students' responses and teachers' views were highly regarded. The students often do not want to choose lecturers who are too harsh, critical, discriminative and disorganized and who do not seem to understand of concepts they are teaching.

Another learning challenge that seemed to emerge form the interviews was that concerning field dependence lecturers vs. field independent learners. According to Samovar et.al, field dependent people "focus on the field (on the whole concept)" while field independent people "concentrate on parts of the field...on impersonal, abstract aspects of stimuli in the environment" (268)

Many of the learners seem to view their lecturers as being holistic. They expect learners to know what is around them. Many of the learners felt that they are not as exposed as their lecturers so a lecturer expecting them to be as holistic as they are is not realistic. They expect their teachers to be lenient on them so that they can get "a good grade". Most of the students are often more focused on the end result and not the means to the end. They choose to do subjects with lecturers that are considered lenient in giving grades or those that do not give "too much work". To them the end justifies the means.

\subsection{Recommendations}

After having analyzed the questionnaire and the subtle nuances of the responses given the researchers had the following views concerning effective learning in USIU.

- Learners must recognize that keeping time is a way of ensuring effective learning takes place. Even though a majority of them have a polychronic view of life, academic schedules are monochronic in nature. The learners must always strive to be in class way before their teachers arrive in class. Teachers should instill time management discipline unto their students.

- Although non payment of fees is not in the teachers' control, further humiliating the learners in the classroom is not necessary. The teacher can pass on information regarding penalties for non payment of fees in a discreet and private manner.

- Knowledge about the cross cultural nature of the learners is necessary. Religious and gender differences are bound to occur in the classroom. Teachers should encourage learners to empathize and respect each other's religion and gender.

- The USIU curriculum has two important courses: Intercultural communication and First Year Experiences which help students understand themselves and the cross cultural challenges they are bound to face in and out of the classroom. During the orientation week, students should be 
encouraged to enroll for these classes as soon as possible. Lecturers too need workshops and seminars in cross cultural communication hat help them understand and appreciate the various needs of the learners in a multicultural education setup.

- Promoting critical thinking in learners is crucial in higher levels of learning. According to Starr (1989), critical thinking is having "the freedom to ask questions and the tools to reason, liberating [ones] mind from unthinking prejudice, and promoting an appreciation for pluralistic democracy". ( $p$ 107). The teacher should not pose as "the know it all"," the alpha and omega" of all learning. The students should be encouraged to bring their knowledge and experiences to the classroom. Developing critical thinking skills helps students explore different perspectives of a subject.

- $\quad$ Encouraging both cooperative and individualized learning process helps develop trusting relationships and respect for their own abilities as well as other peoples' abilities. Both group work and individual assignment increase academic achievements. According to Sapon- Shevin \& Schncedewind (1991), trusting relationship help in "positive interdependence and individual accountability".(P 166)

- The teaching styles of teachers have to be geared towards cross-cultural classroom interaction. According to Gollinick and Chinn (1994) “knowing the cultural background of students helps the teacher determine how to structure the classroom to take advantage of student's natural learning styles" ( $p$ 305). Because it is difficult to change students learning styles, the teacher has the duty of reviewing their teaching styles in order to reach out to all their learners. Variation of learning material so as to embrace learners with different learning styles can help in the learning process.

- Teachers' knowledge of learning difficulties encountered as a result of language diversity is also important. They should recognize that many students new to the language of instruction may not always be able to understand their written and oral instructions. They may also not be able to make appropriate word selections and use language correctly. However, code switching and use of non standard language like Sheng /Engsh should be discouraged in oral and written presentations. Encouraging learners who lack proficiency in English to take supplementary courses in English is paramount. Non-verbal language like dress-code may not easily be dealt with by teachers. However reference to poor dress sense and its power to distract learning can be subtly discussed and debated in class so as to help students understand that an appropriate dress sense can aid in effective learning.

- Teachers should try to expose learners to different ways of getting information and responding to it. Comments by the respondents concerning their inability to access relevant information from reading materials are an indication of students who either lack effective thinking and writing skills or who are simply lazy and do not want to engage in key higher learning endeavors. The learners should be encouraged to get information for 
themselves and sift out what they think is not important. They should also critique what they read so as to form personal opinions.

\subsection{Conclusion}

Overall, the teacher has the biggest role to play in helping students understand that differences in cultural orientations can result in learning problems. These can however be minimized by appreciating and empathizing with others who may have different cultural orientations. The teacher must go out of his way to try and understand that an appreciation of cultural diversity can aid effective learning and classroom communication.

\section{References:}

Cummins, J (1984). Bilingualism and special education: Issues in assessment and pedagogy. Cited in Gollnick, D \& Chinn, P.C. (1994) Multicultural education in a pluralistic Society. (4th. Ed.) New York: Macmillan College Publishing Co.

Geertz, C (1973). The interpretation of cultures. Cited in Valimaa, J. Cultures and identity in higher education research. In Higher education. Vol 36(2) Sept. 1998, pp 119-138.

http://www.jstor.org/stable/34481569(accessed 19/6/08.

Gitonga, D.M. (2008). Functions of code switching in a multilingual classroom in Iraki, F.K Journal of language, technology and entrepreneurships in Africa: A crossdisciplinary review of the United States University (USIU). (Inaugural issue). Nairobi: USIU.

Gollnick, D.M \& Chinn, P.C (1994). Multicultural education in a pluralistic society $4^{\text {th }}$ Ed) Macmillan College Publishing Co. New York.

Gonzalez, A. (1993) Teaching beyond the classroom: business internships in Latin America: Issues in cross cultural adjustment. In Hispania Vol76 (4).Dec, 1993, pp892901

http://www.jstor.org/stable/343927 (accessed 19/6/08.

Kaviti, L (2006) Rejoinder to Alina Rinkanya's article; Sheng literature in Kenya in Indangasi, H. et.al (Eds) The Nairobi journal of literature: Childrens' literature in Kenya. Vol4 March 2006. Nairobi: University of Nairobi

Sapon-Shevin, M \& Schniedewind, N (1991). Cooperative learning as empowering pedagogy. In Sleeter, C. E (Ed.) Empowerment through multicultural education. Pp159178. New York: State University of New York Press.

Starr, J. (1989). The great text book war. In Holtz, I et al (Eds.) Education

And the American dream: Conservatives, liberals and radicals debate the future of education. Pp 96-109. Granby .M.A: Bergin \& Garvey. 